\title{
HYPERVELOCITY DUST PARTICLE IMPACTS OBSERVED BY THE GIOTTO MAGNETOMETER AND PLASMA EXPERIMENTS
}

\author{
F.M. Neubauer', K.-H. Glassmeier', A.J. Coates², R. Goldstein ${ }^{3}$, \\ M.H. Acuña 4 , and G. Musmann's
}

\begin{abstract}
Atmat. We report thirteen very short events in the magwix feld of the inner magnetic pile-up region of comet Halley abarved by the Giotto magnetomerer experiment together with inemeos plasma data obtained by the Johnstone plasma anbyor and the ion mass spectrometer experiments. The events we to dust impacts in the milligram range on the spacecot af the relative velocity between the cometary dust and the pececraft of $68 \mathrm{~km} / \mathrm{sec}$. They are generally consistent with dust inpact ovents derived from spececraft attitude perturbetions by the Giotto camera [Curdt and Keller, private communication]. Their characteristic shope generally involves a sudden decrease - magnetic field magnitude, a subsequent overshoot beyond initi-l field values and an asymptotic approach to the initial cald somewhat reminiscent of the magnetic field signature ofver the AMPTE releases in the solar wind. These observations ive new way of anslyzing wltra-fast dust perticles incident a especcraft.
\end{abstract}

\section{Inroduction}

One of the primary objectives of the cometary missions to P/Halley was the investigation of the dust environment. This was accomplished successfully by the dust experiments PIA and DIDSY on Giotto [Kissel et al, 1986a; Mc Donnell a al, 1986] and on VEGA [Vaisberg et al, 1986; Mazets ot 1., 1986; Simpson et al, 1986; Kissel et al., 1986b] which were desigged to recond individusl dust particles. In addition to the insmanents designed to record single dust impacts the 7.al distribution of dust can be investigated by optical means [Lovasecer-Regourd ot al., 1986].

Apart from these dedicated dust instruments, dust impacts cin also be observed by instruments which were not originally unined for such observations of dust. For example, the ro akiog changes in the spacecraft attitude can be detected by - cabourd carnera and the charge pulses produced can be obarwad by the electric antennas of plasma wave experiments IC anex al., 1983].

Ih this peper we shall present observations of magnetic field and the plasma siganares produced by dust inmes.

A dart impect generally occurred on the dust shield of Giotto or of the protruting appendages [Reinhard, 1986] during the Hey encounter, Because of the high relative velocity - impact leads to a complete vaporization and partial ioniwiven of the projoctile and some of the target material. This

\footnotetext{
1 Insutu für Geophysık und Meteorologie, Universităt zu Köln

Mullard Space Science Laboratory

3 Jea Propulsion Laboratory

- NASA-GSFC

"Insulut fìr Geophysk und Meteorologie, TU Branuschwerg
}

Copright 1990 by the American Geophysical Union.

Paper number 90GL01524

4-8276/90/90CL-01524\$03.00 leads to an expending plasma cloud which produces magnetic field disturbances similar to the AMPTE releases. Using this mechanison dust perticles can be detected as magnetic field disturbances only when an ambient magnetic field is present. This field should then be as high as possible to obtain a large inupect signal. Hence the inner pile-up region around comet Halley [Neubener of al., 1986] is particulorly promising for this purpose because of the high magnetic field and close distance. We shall also present data from the IMS-HERS and the JPA plasson experiments on Giotto which complement the megnetic field observations in an important way.

\section{Observations}

The magnetic field observations were obtained by the Giotto magnetomever experiment which has been described elsowhere [Nowbaver ot al, 1987]. The data are measured at a sampling rate of 28.24 vectors per second corresponding to $\Delta t=35.417$ moec berween successive vectors. The data have been corrected for a slowly varying spacecraft field and for the magneric field of the despin motor. Since the observations reported here have a frequency spectrum extending up to the Nyqvist frequency of the instrumentation at $14.12 \mathrm{~Hz}$ the convolution of the signal with the transfer function of the anti-aliasing filter of the mignetometer implies some signal distortion. For example, the transfer function produces a phase distortion of 90 dezrees and an amplitude reduction by a factor of $\sqrt{2}$ neen the Nyquist fropuency. This disturtion decreases rapidly townds lower froquencies.

The transfer function of the instrument was cocrected exactly for frequencios at $f \approx 0 \mathrm{~Hz}$ of tho magnetic fodd in the non-rotaing inertial frame of referesce. For any anantitative evaluation of the observed timo veriations an appropriate deconvolution will be necessary.

The plasun observations were obtained by the HERS semsar system of the ion mass spectrometer (TMS) experiment [Balsiger of al, 1986] and the fast ion senwor of the Johnowioe plasma andyzar (JPA) experiment [Jobnstone ot al., 1986] onboard Giotzo. Since a full experiment cycle talkes 16 seconds for the HERS-IMS experiment, the plasm observations consist of the readings of the mass channels, energy and directional channets which happened to be scanned during the duration of the event. For the JPA instrument the situntion is the same with an intermal cycle tirne of the spin period of four seconds.

We heve scanned the high time-resolution magetic field dua for conspicuous reversible events of short deration is the time interval from 23:58.00 UT SCET (Specectaft oveat tivat) on March 13, 1986, to 00:08:00 UT SCET on Menct 14, 1986, oorresponding to distances from the comet lese then about 20500 $\mathrm{km}$. A large number of events was obnined, whare mont of then are charecterisad by an abrapt and veveralble devietion

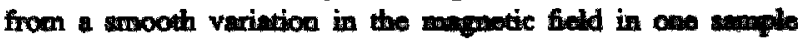
only. We have then further considered only those eveats wh

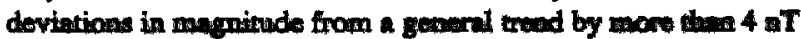

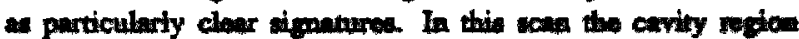


has been excluded because of the reasons given in the introduction. An example of the events identified is given in Figure 1. The magnetic field data are displayed in Halley-centered solar-ecliptic coordinates (HSE-coordinates). The sharp dip in the magnetic field suggests that the data have been undersampled. Therefore the dip could well be deeper than apparent in the dats. The event shown in Figure 1 stanted at the time 00:00:46.9 on March 14, 1986.

Table 1 lists all the thirteen events discovered in the magnetic field data. The general behavior is an initial decrease with a subsequent recovery and sometimes an overshoot. The second column of the table shows the time of the minimum magnetic field. Event six has been disturbed by interference from the stepper motors of the Halley Multicolor Camera (HMC). Event eleven shows no minimum. The time of the maximum is given. A minimum could also have occurred in this case but missed because of the low sampling rate or the convolution with the anti-aliasing filter.

The third column compares our events with the only published list of dust impacts near the comet [Poster presentation by W. Curdt and H.U. Keller, Bamberg 1989] which also contained mass estimates. Their dust impact events were detected by dynamical perturbations of the spacecraft detected by the camera HMC. After closest approach at 00:03:02 UT SCET no comparison can be made because the camera stopped its operations. Four HMC events occurred inside the cavity where the magnetometer is "blind". There were six HMC events before entry into the cavity, two of which, ie. events one and six, agree with our events. Event 1 was analyzed in some detail already using DMS, JPA and DIDSY observations [Goldstein et al., private communication, 1989]. Events one and six are characterised by masses greater than $5 \mathrm{mg}$ according to Curdt and Keller. Three of the HMC events not seen by the magnetometer were due to much smaller particles in the milligram range. The only impact due to a large particle not seen by the magnetometer occurred approximately 103 seconds before closest approach.

The fourth column gives the distance whereas the column labelled "Type" describes the phenomenological type. When the decrease to the minimum occurred in one step it is called abrupt (a). Otherwise it is labelled gradual (g). The field could vary by going down as a rule or by going up in event eleven.

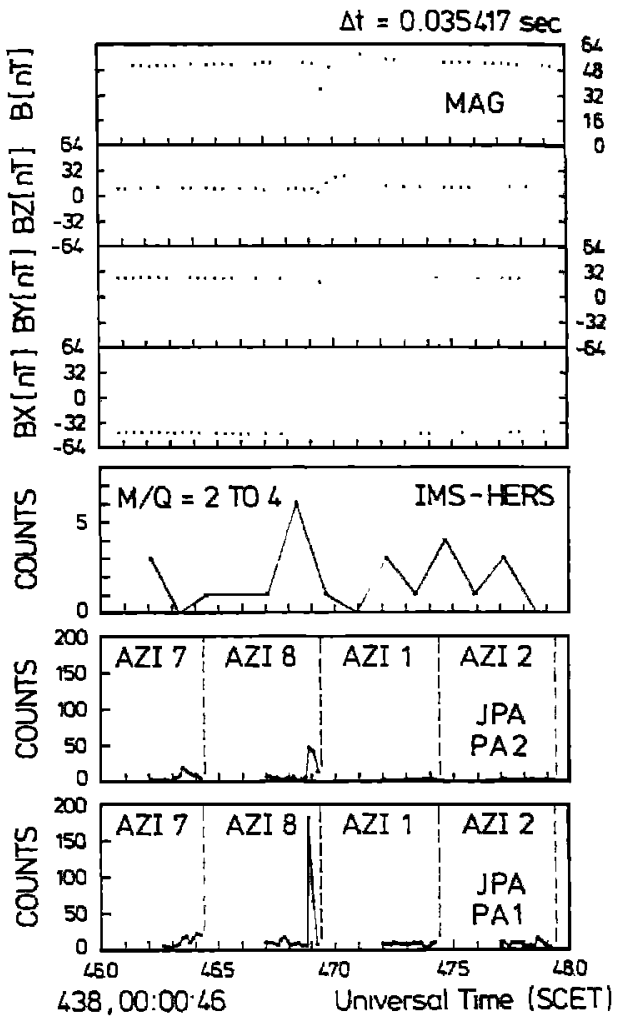

Figure 1: Magnetic field and plasma observations of der im pact event two. The magnetic field vectors are represestod in Halley centered solar ecliptic coordinates at a time resolutine ef 28.24 vectors per second. The dath of the ion miss specture eter HERS sensor system are shown in raw data cowents peak corresponds to M/Q $=2$ presumably $\mathrm{H}_{2}^{+}$. The Jot plasma analyzer data also given in raw dam counts are stow for a spacecraft polar angle range PA 1 pointing rowruts comet at 20-72 degrees from the spacecraft - comet bine an PA 2 somewhat removed from that direction at 72-124 do from the spacecraft - comet line. The vertical dashed bies in the JPA-panels indicate the dividing lines between counts obtained in azimuthal sectors $7,8,1$ etc. For further discum see text.

TABLE 1. Dust Impact Events Observed by Giotto Near Closest Approach (For Explanation see Text)

\begin{tabular}{cccccccc}
\hline $\begin{array}{c}\text { Event } \\
\text { Number }\end{array}$ & $\begin{array}{c}\text { Time of } \\
\text { UT SCET }\end{array}$ & & $\begin{array}{c}\text { Association } \\
\text { With }\end{array}$ & & $\begin{array}{c}\text { Distance } \\
10^{3} \mathrm{~km}\end{array}$ & Type \\
& Minimum & HMC & IMS & JPA & & & \\
\hline 1 & $23: 59: 26.0$ & yes & yes & yes & 14.8 & $\mathbf{g}$, down \\
2 & $00: 00: 47.0$ & no & yes & yes & 9.3 & a, down \\
3 & $00: 00: 58.4$ & no & yes & "blind" & 8.5 & a, down \\
4 & $00: 01: 32.5$ & no & yes & yes & 6.1 & a, down \\
5 & $00: 01: 47.9$ & no & yes & yes & 5.1 & a, down \\
6 & $00: 01: 52.2$ & yes & yes & yes & 4.8 & a, down \\
7 & $00: 04: 02.3$ & - & - & yes & 4.2 & $\mathbf{g}$, down \\
8 & $00: 04: 06.5$ & - & - & yes & 4.5 & a, down \\
9 & $00: 04: 12.2$ & - & - & yes & 4.8 & a, down \\
10 & $00: 04: 19.0$ & - & - & blind" & 5.3 & $\mathbf{g}$, down \\
11 & $(00: 04: 31.6)$ & - & - & yes & 6.2 & a, up \\
12 & $00: 04: 54.8$ & - & - & yes & 7.7 & $\mathbf{g}$ down down \\
13 & $00: 06: 10.7$ & - & - & yes & 12.9 & a, down \\
\hline
\end{tabular}


We mentioned already that in the latter case a short minimum $\rightarrow$ brve escaped detection because of its small width.

Futher important evidence for the nanre of the magnetic fold events as being due to dust impacts has been obtained by to plasma observations. The IMS-HERS instrument identified the events from 1 to 6 before it died between events 6 and 7. Figure 1 also shows the MMS-HERS data for event two. The experiment was in the L-mode when the event occurred as a poak in count rate well above the purely iooospheric count nese counts shown in Figure 1 give raw counts at $M / Q=$ 2 procamably due to $\mathrm{H}_{2}^{+}$.

We note that the background number of counts is much less me. The number of counts before and after the maximum is typical for the cometary ionosphere at this distance. The acaracy of the time relative to the magnetometer data is probably wetter than 0.1 seconds.

All events except for events 3, 4, 6 and 10 were also idenifed as very short peaks in the energy and azimuth scans of te JPA experiment with a strong undersarmpling of the plasma dbed spectra. However, for events three and ten the magnemer times show that the JPA was in the high voltage flyback which lasts about 16 milliseconds and in which the JPA is "The the interval of "blindness" could be even longer, becrese the flyback is followed by the high energy spectral cous in the subsequent energy scans starting from $20 \mathrm{keV}$ dowawards. If the energy spectrum of the plasma cloud did sot extend up to $20 \mathrm{keV}$ the "blind" interval could have lasted bager. Thus given the identification by the IMS-HERS these new have the same signatures as the other events. The situatica is different for events four and six which are characterised by increased count rates for almost a spin period in contrast to te deration of a few 10 milliseconds in the other cases. They - $\rightarrow$ therefore constitute a different type of event.

For our example in Figure I the counts in the polar angle manl PA 1 pointing towards the comet and in the adjacent -avil PA 2 are given as a function of time. Whereas the manements in the polar angle intervals PA 1, PA 2 etc. are simultaneously, the arimuthal angles are scanned by the mina of the spacocraft with two energy scans one after anaperimposed in each azimuthal bin. Thus at a given time in Figure 1 in every polar angle interval the counts correspond - jest case aximuthal angle interval and one energy channel. Wh the two energy scans per aximuthal bin separated by 0.25 mocads the counts given are the sum of the counts around the the of tho plot and 0.25 seconds, i.e. a sixteenth spin rotation, arier. The azimuthal bins seven and eight partly shown in Fyore 1 are followed by aximuthal bin one in which the exparienent aperture looks in the solar direction. The data of all wease are consistent with the picture of a plasma cloud with prricies coming from the comet at all arimuthal angles and - a broed range of energies. Hence the azimuthal bin of the marement does not exclude the presence of perticles in other Also the energy chamels oxcited are a consequence of the experimeat cycle and do not indicate a narrow energy preturn but rather a short time duration. With the event $O C$ a ing in two consecutive energy bins it mast have occurred mond the dividing time 46.92 s or 0.25 seconds endier in this thes.

A fow mond on the reletive timing of the experiments are

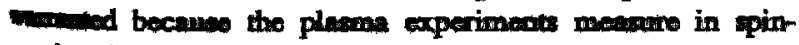

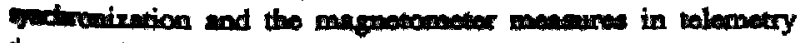

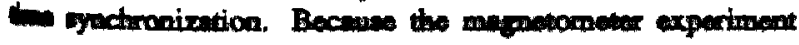

also transmits the angle of rotation from the last sun referesce pulse, the times of occurrence of the sun reference pulse have been taken as an accurate means to synchronize the dan.

\section{Discussion}

We have detected thirteen reversible magnetic field and plasma events of very short duration in the inner magnetic pilo-up region of comet Halley at distances of less than $20500 \mathrm{~km}$. They can be clearly distinguished from camera interference signals because of the clear periodicity of the latter signals and their special form. We see no possibility to explain these events by plasma dynamics unrelated to dust except perhaps for the broad events four and six which have a broed platema signature. The dust impact nature of the events has been confirmed by comparison with plasma observations and attitude changes observed by the carnera [Curdt and Keller, private communication] and in the case of event one by comparison with the DIDSY experiment [R. Goldstein, privaxe communication, 1989].

The phenomenology of an event is exemplified by event two in Figure 1 and can be described as follows: A short pulse in the plasms count rates is followed first by a decrease in magnetic field magnitude, an overshoot and an asymptotic approach to the undisturbed magnetic field. The magnetic field bebavior is similar to the one observed after the AMPTE releases in the solar wind [Liihe et al, 1986].

We propose the following physical scenario for the events with the possible exception of event four: The lerge nelative velocity of an impacting Halley dust particle implies a binetic energy of $24.4 \mathrm{eV} / \mathrm{arnu}$ sufficient to vapocize, dissociate and ionize the dust perticle and part of the target manterial. The indtial dense plasma cload expands rapidly with the initial stages described e.g. by Hocrung and Drapatz [1981] for dest perticles in the milligram range. At the same time the center of gravicy of the cloud initially starts to move apray from the spacecraft towards the comet with a velocity relative to Giotro which is a large fruction of the initial relative dust spececraft velocity $w=68.4 \mathrm{~km} / \mathrm{s}$. After an initial phase in which the ionization is described by equilibrium conditions the time scale of recombintion starts to exceed the expancion scale according to Hornang and Draparz [1981]. The ionization state is then estentially frozen in. A little later the plasma perticles reach the plasma andyzers. When the collision mean free path becomes greaner than the cloud dimater the fllow will become collisionless. At win even later time the electrons becono frowen to the magnetic field. From this time on the magnetic field in the choud's interior docreases rapidly as observed by the apececraft inside the clour. At the time the ambient magnetic feld is piled up at the "bow" of the cloud and the cloud's cenver of gravity starts to accelerate doe to the interaction with the flow of unperturbed ionospheric plasma. Thess the cernser of gravity of the cloud is initislly moving awry from the pacocraft followed by a phase when the cloud revares difection and moves again townds the spacecruft. The ovemboot in the magnetic field is obeerved when the cloud's pillow region is reached with a subsequent final decresse to the bitial anbivent field value. A theoretical trembent of this problem is outuide the scope of this observational peper and will be reportad in the future

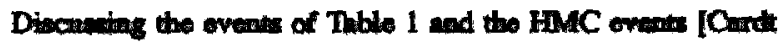

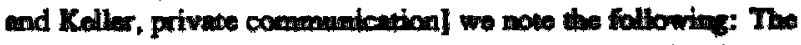

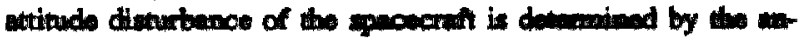


gular momentum of the incident dust particle with respect to the center of gravity of the Giotto spacecraft and the details of the interaction. The angular momentum is given by $\mathrm{M} d$ $w$, where $M$ is the mass and $d$ the distance from the spacecraft axis. Since the relative velocity $w$ is constant the quantity characterising the impact is $\mathrm{M} \mathrm{d}$. On the other hand the detection as a magnetic field event requires a large mass of the plasma cloud given by $\mathbf{M}$ times the final degree of ionization $\alpha$. The events one and six can be associated with large mass events observed by $\mathrm{HMC}$ or more precisely large products $\mathrm{M} d$. They are also the most dramatic magnetic field events. Events two through five must be characterised by small $M d$ to explain non-detection by the camera but sufficient $M \alpha$ to be detected by the magnetometer. The HMC events not seen as an event in the magnetic field are characterised by small $M$ and therefore $M d$ except for one. In this case the mass determination may be inaccurate or the degree of ionization is unusually low perhaps indicating that the particle consisted of a material with high ionization potential or strong recombination.

Event four because of the Iong duration of the plasma signal may be due to a plasma dynamics feature of an unidentified nature. Its minimum variance characteristics are consistant with a planar sheet. Combining all the evidence for event six including the analysis by Neubauer [1988] it seems that a weak outward propagating shock occurred almost simultaneoulsy with a dust impact and a camera disturbance.

\section{Summary}

We have investigated thirteen reversible magnetic field events of very short duration in the inner magnetic pile-up region of comet Halley at distances less than $20500 \mathrm{~km}$ from the comet. Except possibly for two cases these events were accompanied by short ion bursts when observations by the Johnstone plasma analyzer and the ion mass spectrometer on Giotto were available. They are interpreted as the magnetic and plasma signatures of plasma clouds generated by hypervelocity impects of cometary dust particles on the Giotto spacecraft. This is consistent with attitude disturbances observed by the Giotto camera experiment. The signarure of these events in the magnetic field is similar to that of the AMPTE-releases in the solar wind. A quantitative interpretation based on modelling in the funure will open a new possibility to diagnose the important kinematic and mass properties of the plasma clouds due to hypervelocity impact.

Acknowledements.: The work of F.M. Neubauer, KH. Glassmeier and $G$. Musmann was supported financially by the German Bundesministerium für Forschung and Technologie. The work by M.H. Acuña and R. Goldstein was supported by NASA. The work by A.J. Coates was supported by the Science and Enginecring Research Council of the U.K.

\section{References}

Balsiger, H., et al. The Giotto ion mess epectumeter, in "The Giotto Mission - Its Scientific Investigations", ESA SP-1077, 129-148, 1986.

Gurnett, D.A., E. Griln, D. Gallagher, W.S. Kurth, and F.L. Scarf, Micron-sized particles detected near Suturn by the Voyager plasma wave instrument, lcarus, 53, 236-254. 1983.

Hornung, K., and S. Drapate, Reaidual ionisation after impect of lange dust particlos, in "Tho Comet Halley Probe Plasan Baviromene", ESA SP-155, 23-38, 1981.
Johnstone, A., et al., The Giotto three-dimensional positive ion analyser, in "The Giotto Mission - Its Scientific in vestiagations", ESA SP-1077, 15-32, 1986.

Kissel, J., et al., Composition of comet Halley dust perticles from Giotto observations, Nature, 321, 336-337, 1986.

Kissel, J., et al., Composition of comet Halley dust particle from Voga observations, Nature, 321, 280-282, 1986.

Levasseur-Regourd, A.C., J.L. Bertaux, R. Dumont, M. Pewtou, R.H. Giese, F. Giovane, P. Lamy, JM. Le Blwac, A. Llebaria, and J.L. Weinberg, Optical probing of conat Halley from the Giotto spacecraft, Nature, 321, 341-344, 1986.

Liihr, H., D.J. Southwood, N. Klöcker, M. Acuña, B. Hen ler, M.W. Dunlop, W.A.C. Mier-Jedrzejowicz, R.P. Rija beck, and M. Six, In situ magnetic field measurements during AMPTE solar wind $\mathrm{Li}^{+}$releases, J. Geophys. Res. 91, 1261-1270, 1986.

Mazets, E.P., R.L. Aptekar, S.V. Golenetskii, Yu.A. Grya A.V. Dyachkov, V.N. Iyinskii, V.N. Panov, G.G. Perow, A.V. Savvin, R.Z. Sagdeev, I.A. Sakolov, N.G. Khavenson, V.D. Shapiro, and V.I. Shevchenko, Nature, 321, 276 278, 1986.

Mc Donnell, J.A.M., et al., Dust density and mass distribution near comet Halley from Giotto observations, Nonure, 321, 338-341, 1986.

Neubauer, F.M., The ionopause transition and boundary lyyers ar comet Halley from Giotto magnetic field observations, J. Geophys. Res., 93, 7272-7281, 1988.

Neubauer, F.M., M.H. Acuña, L.F. Burlaga, B. Fraska B. Grankow, F. Mariani, G. Musmann, N.F. Ness, H.U. Schmidt, R. Terenzi, E. Ungstrup, and M. Wallis, The Giotto magnetometer experiment, J. Phys. E., 20, 714 720, 1987.

Neubaner, F.M., K.H. Glassmeier, M. Pohl, J. Raeder, M.H. Acuñn, L.F. Burlaga, N.F. Ness, G. Musmann, F. Marian, M.K. Wallis, E. Ungstrup, and H.U. Schmidt, First reselis from the Giotto magnetometer experiment at comet Halley, Nature, 321, 352-355, 1986.

Reinhard, R., The Giotto encounter with comet Halley, Nature, 321, 313-318, 1986.

Simpson, J.A., R.Z. Sagdeev, A.J. Tuzzolino, M.A. Petcina L.V. Ksanfomality, D. Rabinowitz, G.A. Lentz, V.V. Afonin, J. Enô, E. Keppler, J. Korosokov, E. Petrova, L. Szabo, and G. Umlauft, Dust counter and mass andyar (DUCMA) measurements of comet Halley's from Voge spececraft, Nature, 321, 278-280, 1986.

Vaisberg, O.L., V.N. Smimov, L.S. Gom, M.V. Iovlev, M.A Balikehin, S.I. Klimov, S.P. Savin, V.D. Shapiro, and VI Shevchenko, Nature, 32I, 274-276, 1986.

F.M. Neubauer and K-H. Glassmeier, Institut fitr Goophy und Meteorologie, Universithit zu Köln, Albertus-Magnems-Phy D-5000 Koln 41, Federal Republic of Germany.

A.J. Comes, Mulland Space Science Laborntory, Fotalum St. Mary, U.K.

R. Goldstein, Jet Propulsion Laboratory, Califaria butwm of Techaology, Pasadem, CA, U.S.A.

M.H. Acuña, NASA-GSFC, Greenbelt, U.S.A.

G. Musmann, Intitut ftr Geophysik und Matoonologin, W Braunschweig, F.R.G.

Received Janumiry 15, 1990; acoprod May 11, 1990 